\title{
Systems Analysis Approach for the NASA Environmentally Responsible Aviation Project
}

\author{
William M. Kimmel ${ }^{1}$ \\ NASA Langley Research Center, 1 N. Dryden St. Mail Stop 442, Hampton, VA 23681
}

\begin{abstract}
This conference paper describes the current systems analysis approach being implemented for the Environmentally Responsible Aviation Project within the Integrated Systems Research Program under the NASA Aeronautics Research Mission Directorate. The scope and purpose of these systems studies are introduced followed by a methodology overview. The approach involves both "top-down" and "bottoms-up" components to provide NASA's stakeholders with a rationale for the prioritization and tracking of the ERA portfolio of technologies. The ERA technologies enable the future fleet of aircraft to operate with a simultaneous reduction of aviation noise, emissions and fuel-burn impacts to our environment. Examples of key current results and relevant decision support conclusions are presented along with a forecast of the planned analyses to follow.
\end{abstract}

\section{Nomenclature}

$\begin{array}{ll}A N O P & =\text { Aircraft Noise Prediction Program } \\ A E D T & =\text { Aviation Environmental Design Toolset } \\ C A E P & =\text { ICAO committee for Aviation Environmental Policy } \\ C O_{2} & =\text { Carbon Dioxide } \\ d B & =\text { Decibels } \\ D D R & =\text { Direct-drive Turbofan Propulsion Technology } \\ E R A & =\text { Environmentally Responsible Aviation Project } \\ F L O P S & =\text { Flight Optimization and Performance Sizing tool } \\ G T F & =\text { Geared Turbofan Propulsion technology } \\ H L F C & =\text { Hybrid Laminar Flow technology } \\ H W B & =\text { Hybrid Wing Body } \\ N P S S & =\text { Numerical Propulsion Simulation System Tool } \\ N R A & =\text { NASA Research Announcement } \\ N O_{x} & =\text { Nitrogen Oxides } \\ N L F & =\text { Natural Laminar Flow technology } \\ O W N & =\text { Over-wing Nacelle aircraft concept } \\ P R S E U S & =\text { Pultruded Rod Stitched Efficient Unitized Structure }\end{array}$

\section{Introduction}

$\mathrm{T}$ his conference paper and presentation were prepared by invitation of the chairman of the Environmental Impacts and Green Technologies session for the $3^{\text {rd }}$ AIAA Atmospheric and Space Environment Conference. The Purpose and methodology developed in support of the ERA will be described. The scope of activities and the team will also be described. This will be followed by a presentation of current results and what are their implications to the project decision makers. A description of the "top-down" approach will be the major focus of this paper with a minor segment illustrating what the "bottoms-up" approach involves by means of an instructive example technology sub-set. Finally, we present an introduction of the team's current approach using a probabilistic analysis in order to increase our insight into the ERA project portfolio's future potential.

\footnotetext{
${ }^{1}$ Chief - Aeronautics Systems Analysis Branch, MS 442, LaRC, Hampton, VA 23681, AIAA Senior Member 1 American Institute of Aeronautics and Astronautics
} 


\section{Purpose and Scope of Systems Analysis for ERA}

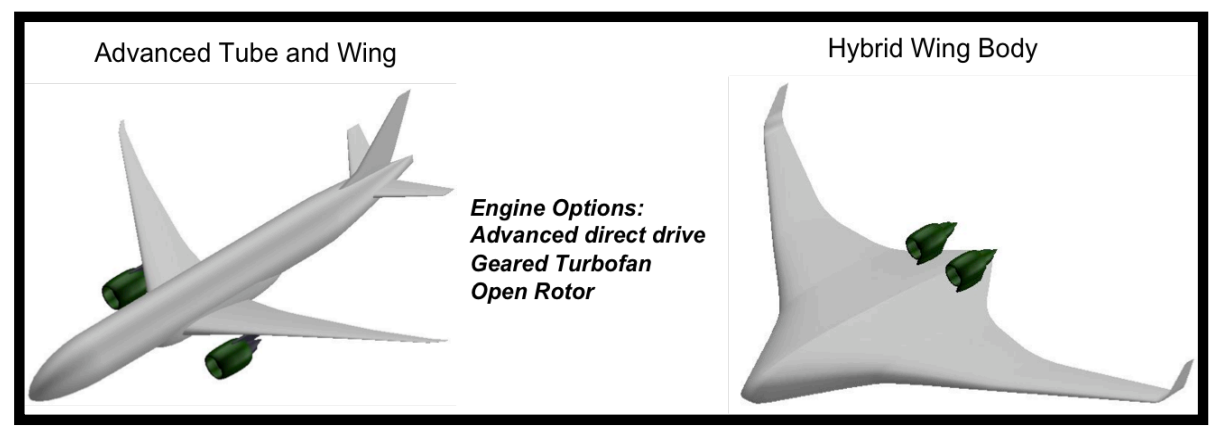

FIGURE 1. Initial Technology Collectors

The author presents the collective efforts of number of partners. They include: NASA (especially Subsonic Fixed Wing Project), Mr. Craig Nickol - ERA systems analysis lead. Outside of NASA the members include: FAA, Georgia Tech ASDL, Purdue, MIT, GE Aviation systems, Pratt \& Whitney UTC, Volpe Center, ICAO/CAEP. These partnerships are coordinated and funded under a number of NASA NRA awards and leverage a number of long-term systems analysis frameworks that have undergone extensive prior validation and/or verification, which have been vetted by the relevant subject matter. The purpose of these activities, it is simply to provide our Agency stakeholders a decision support activity that tracks environmentally responsible aviation technologies and assesses their potential impact toward simultaneously achieving the technical challenge goals of the ERA Project. There are two conceptual approaches by which this is achieved in the current systems analysis approach. The "top-down" element examines combinations or suites of technologies under the ERA project and develops an impact or measure at the systems level towards the ERA project goals for simultaneously reducing aviation Emission, Noise and Fuelburn. For the "bottom-up" approach, the project has developed a $3^{\text {rd }}$ technology database from multiple sources into a 140-page internal project document in August 2010. This phase 1 database includes technology description,

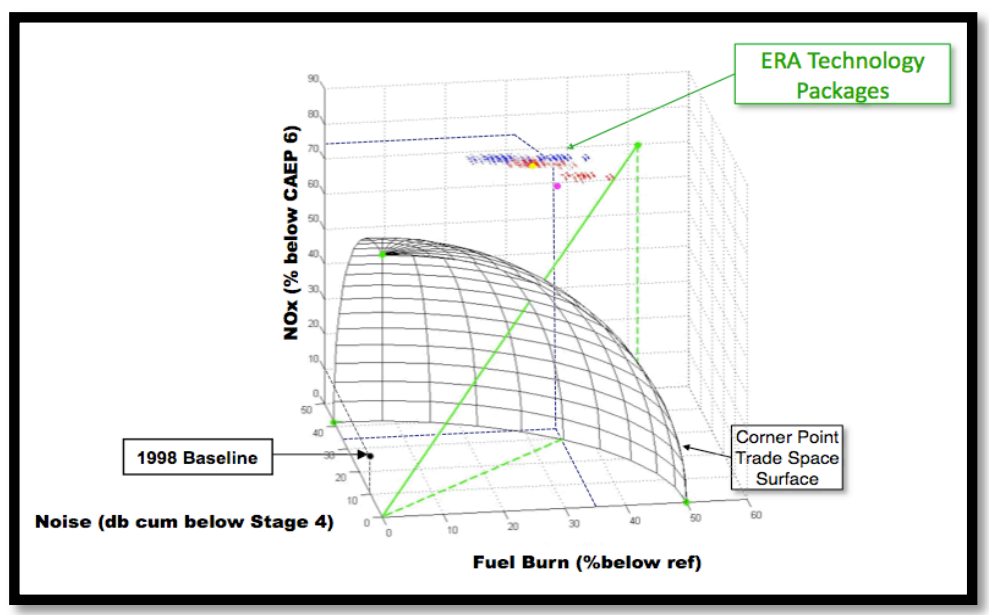

Figure 2. ERA Project Goals and design space visualization

current and projected technology readiness levels, compatibility interaction matrix for 65 technologies, projected benefits and impacts, and finally the assumptions and modeling approach that the project will utilize within the analysis framework. The database filtered technologies that were either too low or too high in technology readiness level (TRL) with respect to the NASA ERA Project plan. It includes 19 airframe technologies and 46 propulsion technologies. Lastly, the database was verified and vetted by the entire ERA project and partner members including the FAA/CAEP partners, airframe primes and engine primes. 


\section{Methodology Overview}

Progress toward project goals and tracking are achieved through the use of several generic advanced aircraft concepts that serve as technology collectors for these assessments. Briefly, they are included in figure 1 which shows one generic advanced tube and wing, however there are two versions being utilized. A single aisle class and a large twin aisle along with the advanced Hybrid Wing Body (HWB) concept are each capable of having single and/or suites of technologies applied where the NASA standard toolset (NPSS/WATE, FLOPS, ANOPP) are used to estimate fuel burn, noise and emissions. These estimates, in turn, are input into the Environmental Design Space codes (EDS) ${ }^{2,6,11}$ in the FAA's Aviation Environmental Design Tool (AEDT) ${ }^{2,6,11}$ global toolset to develop future fleet level global impact estimates. As the project matures, additional technology collectors will be developed and added to this initial set by a combination of NRA and in-house activities. Utilizing the technology database as input, the systems analysis study team is currently in the process of assessing the resultant 3600 combination of "feasible concepts" involving these technology collectors with the deterministic output which includes full performance envelope, fuel burn, noise and emissions estimates for these vehicle-technology combinations. These results are assembled in a combinatorial space as a cloud of point solutions to aid the team in identifying if a potential Pareto frontier exists. In addition, a probabilistic approach is also being employed where the confidence in meeting a particular metric is given a notional probability distribution function. This permits the estimation of sensitivity and likelihood of a particular technology suite meeting the project metrics. Additionally, it serves as a diagnostic index of technology development risk for the project leadership. Current results will be shown next.

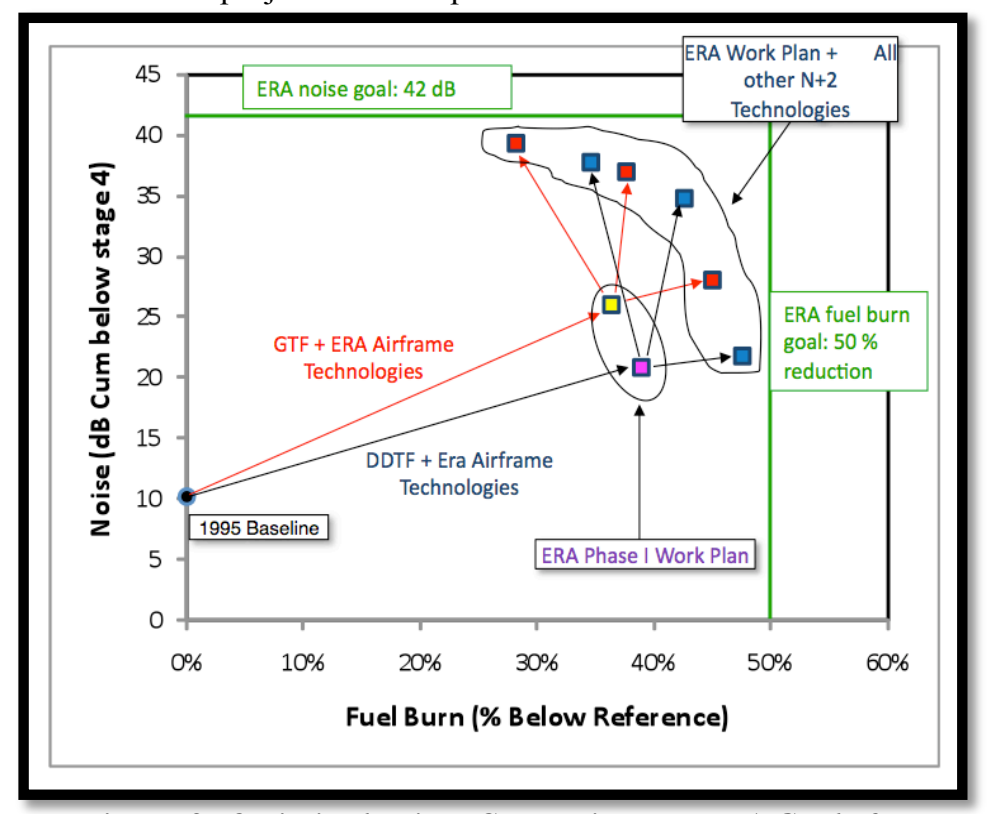

Figure 3. Optimized points Comparison to ERA Goals for Advanced Large Twin Aisle Tube and Wing

\section{Technology Ranking and Initial Results}

Figure 2 shows the combined space mapping of the three primary ERA project objectives along with a desired end state goal for the project using the Advanced Single aisle tube and wing collector. The spherical quadrant surface is notional at the moment and the calculated estimates for a select combination are shown in red and blue. These series of data represented a combination of airframe and engine technology suites which were selected from the ERA database to identify a 'most likely' best set of technologies where all were matured to estimated TRL and $100 \%$ likelihood of meeting performance objectives at technology/subsystem level. From the figure the following conclusion was made. The best suite of technologies applied to an advanced tube and wing single aisle will not result in a future achievement of the ERA project goals. A second observation from this series of computations implies that for the simultaneous achievement of the ERA project goals, the technologies themselves must each exceed their current independent performance and/or emissions reduction estimates to result in a vehicle system level benefit that scales up to the fleet level objectives. 
The ERA phase I technology portfolio trade space can be further examined to compare trade-offs with either single performance goal by integrating into a vehicle system collector. Essentially, Figure 3 is a planar slice through the data in Figure 2. This permits a more refined view of how each portfolio performs on coupled objective goals

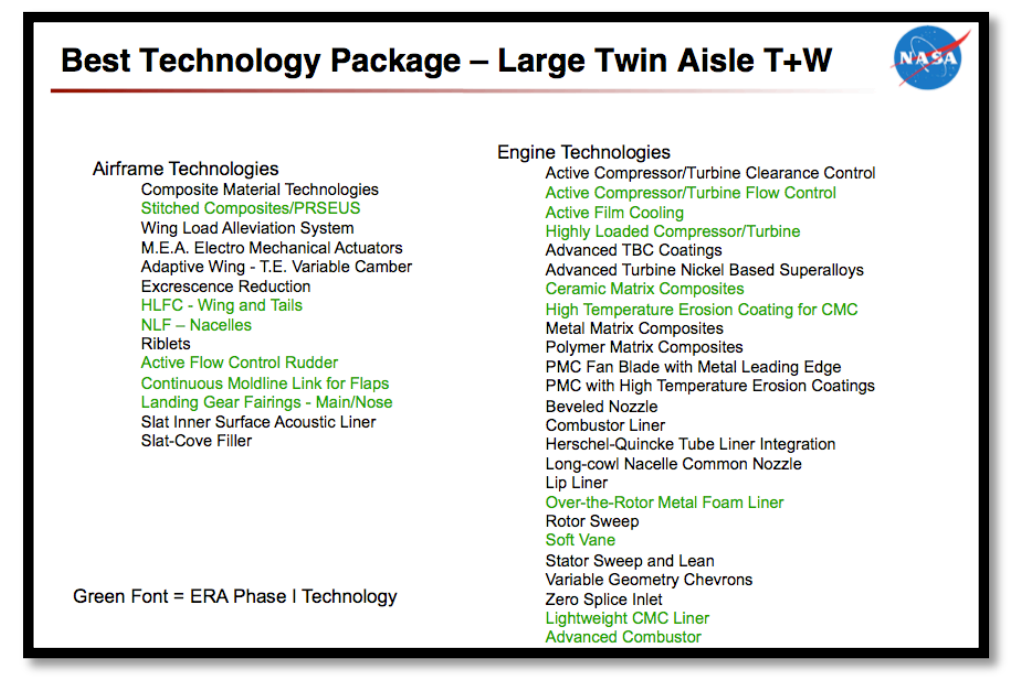

Figure 4. Best Technology Package Forecast for Large Twin Aisle Advanced Tube and Wing technology collector 1

The ERA phase I plan technical portfolio (Figure 4) is estimated to make significant improvements in noise and fuel burn. While the ERA phase I plan plus all other potential N+2 technologies (from the Subsonic Fixed Wing Project) applied to an advanced tube and wing are not forecast to meet the ERA project goal from this noise/fuel burn tradeoff. Finally, we conclude that a configuration change is required to meet the ERA goals. From this we continue to examine the potential for Hybrid Wing Body configurations to provide the system level benefits and subsequently, fleet/global level noise, emission and fuel burn reduction potential.

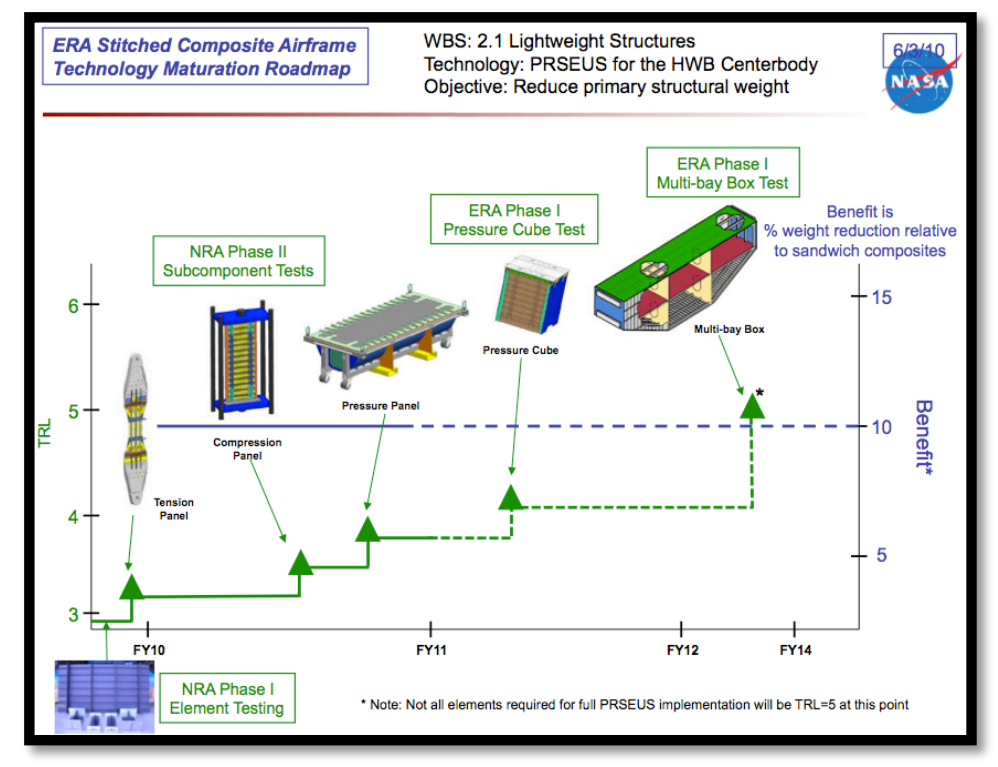

Figure 5. PRSEUS Example of Technology tracking from bottom-up 


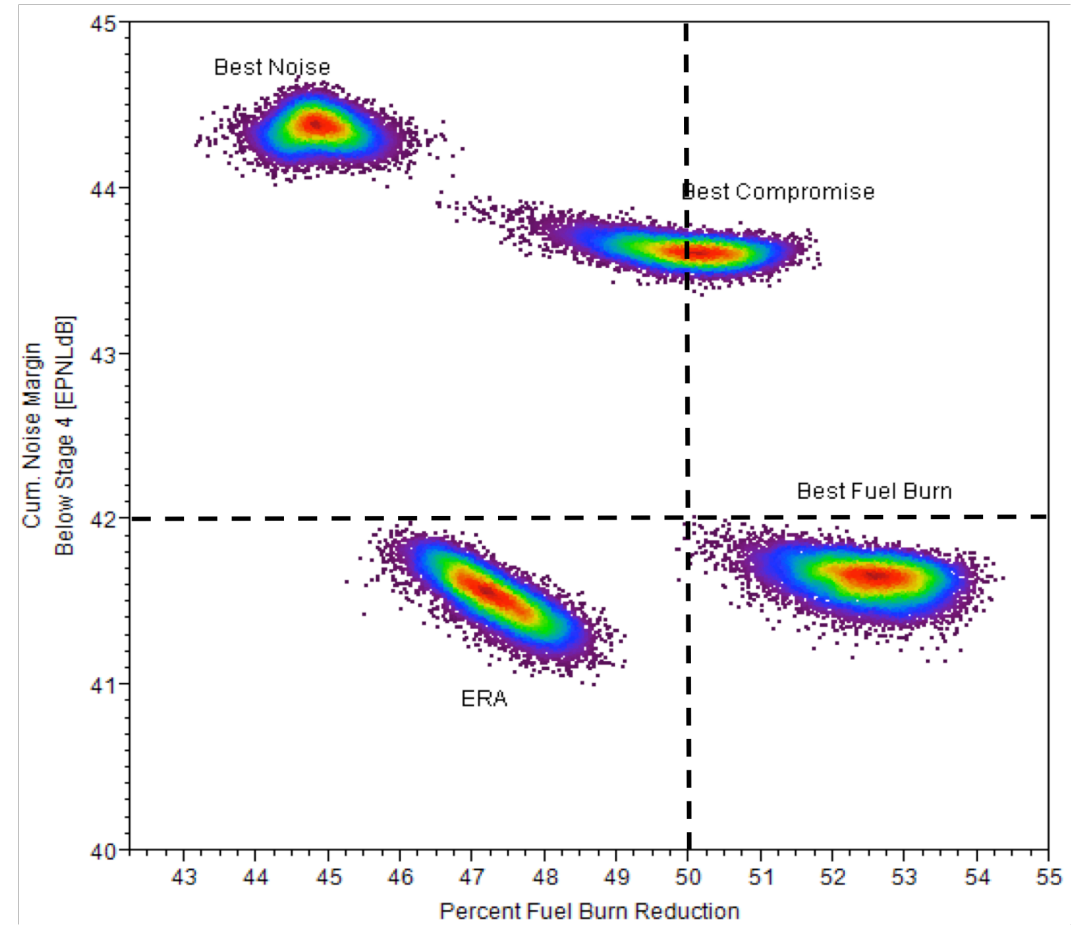

Figure 6. All Tube and Wing Configurations in Probabilistic Space against 2 ERA goals

The other key element in the systems analysis approach to the ERA project is the "bottoms-up" technology identification and tracking activity. In short, this examines the planned research implementation of the suite of ERA technologies and upon completion of key milestones, as each technology is matured with a corresponding reduction in uncertainty with respect to the estimated performance benefits alone and at the sub-system, vehicle system and global fleet levels. These roadmaps are in turn, refreshed periodically with the evolved TRL level, refined system level integrators/collectors to continuously refine both the forecast measures performance against the project goals and to inform the technologists towards squeezing down the uncertainty gaps between the "top-down" and "bottomup" analysis for each technology. Figure 5 shows and example of a highly promising technology involving stitched and pultruded composites for use in non-circular fuselage application. This is an example of single current technology focus area for ERA project research and development roadmap. It also shows the key milestones and TRL levels where this building up from a technology towards systems level benefits is planned to occur. From the studies conducted so far, the team concludes that multiple suites of technologies will be required in order to meet the ERA project objectives.

\section{Conclusion}

The current systems analysis purpose, scope, approach and methodology were presented. Key recent results and conclusions of import to ERA project decision-makers and stakeholders were shown. The trade space analyses yield results that show advanced tube and wing configurations will benefit from technologies being researched under the ERA project, but without a configuration, new system level concept/technology, will fall short of the challenge goals of the NASA ERA project. An ongoing technology tracking and identification process was also described to aid the project to reducing system level benefit uncertainty overall to ensure the technology portfolio investment meets or exceeds the project goals. It is expected that further data will be presented on these analyses as it becomes available from the team.

\section{Acknowledgments}

"W.M.Kimmel thanks the chairman for the invitation to present this material on behalf of the ERA Systems Analysis Team members including the technical assistance of Mr. Craig Nickol, and the Georgia Tech ASDL research team: Dr. Jeff Schutte, Dr. Hernando Jimenez, Mr. Carl Johnson, and Dr. Michelle Kirby. 


\section{References}

1. Collier, F., Thomas, R., Burley, C., Nickol, C. Lee, M., Tong, M. "Real Solutions For Environmental Challenges Facing Aviation" ICAS-2010-1.6.1

2. Becker, K., Kirby, M., Nam, T., Mavris, D. “A Process for Future Aviation Environmental Impacts: Surrogate Fleet Analysis Approach for NextGen”, AIAA-20096934

3. Nickol, C., McCullers, A., "Hybrid Wing Body Configuration Systems Studies", AIAA-2009-931

4. Nam, T., Burdette, G., Kirby, M., Mavris, D., Bonnefoy, P., Hansman, R., Hileman, J., Waitz, I., Yutko, B., "An Investigation of the Potential Implications of a Emission Metric on Future Aircraft Designs" ICAS-2010-5.9.2

5. Guynn, M., Berton, J., Fischer, K., Haller, W., Tong, M., Thurman, D., “ Analysis of Turbofan Options for an Advanced Single Aisle Transport Aircraft”, AIAA2009-6942

6. Kirby, M., Barros, P., Mavris, D., "Enhancing the Environmental Policy Making Process with the FAA's EDS Analysis Tool" AIAA-2009-1262

7. M. Kirby, K. Becker, S. Isley, et al "DEVELOPMENT OF AN INTERACTIVE CAPABILITY TO TRADE OFF NEW TECHNOLOGIES AND FUTURE AIRCRAFT TO REDUCE AVIATION ENVIRONMENTAL IMPACTS”, ICAS 2010-4.10.2

8. Nam, T., Soban, D., Mavris, D., “A Non-Deterministic Aircraft Sizing Method under Probabilistic Design Constraints”, AIAA-2006-2062

9. Ran, H., Mavris, D., "A Framework for Determination of the Weak Pareto Frontier Design Solutions under Probabilistic Constraints", AIAA-2006-6960

10. Leavitt, L., Collier, F., "Integrated Systems Research Programme: Environmentally Responsible Aviation (ERA) Project", ICAO Colloquium on Aviation and Proceedings Climate Change Proceedings, 12-14 May 2010, Montreal, QC, http://www.icao.int/CLQ10/Docs/3 Leavitt Nasa.pdf

11. Schutte, J., Jimenez, H., Mavris, D. “ Technology Assessment of NASA Environmentally Responsible Aviation Advanced Vehicle Concepts”, 49th AIAA Aerospace Sciences Meeting, AIAA-2011-6, January 2011.

12. Jimenez, H., Schutte, J., Mavris, D. "System Readiness and Risk Assessment for Advanced Vehicle Concepts - Discussion of Fundamental Concepts “, 49th AIAA Aerospace Sciences Meeting, AIAA-2011-423, January 2011.

13. Kestner, B., et.al. "Ultra High Bypass Ratio Engine Sizing and Cycle Selection Study for a Subsonic Commercial Aircraft in the N+2 Timeframe", ASME Turbo Expo, GT2011-45370, June 2011. 